ARTICLE

https://doi.org/10.1057/s41599-019-0364-0

\title{
Co-designed strategic planning and agile project management in academia: case study of an action research group
}

\author{
Enric Senabre Hidalgo ${ }^{1 \star} \&$ Mayo Fuster Morell ${ }^{2 \star}$
}

\begin{abstract}
Strategic planning, a standard activity for project management in different areas and types of organisations, can contribute to improving the dynamics of collaboration in academia, and specifically in research processes. This paper joins the still scarce studies on strategic planning within research groups, contributing to the field of both team science and organisational management from a social sciences perspective and "strategy-as-practice" paradigm. Through the case study of an action research group, after the experimental cocreation of its long-term strategy involving different participatory design methodologies, we quantitatively analyze how this process influenced communication and group relations, both internally and in relation to its participation in the ecosystem with other stakeholders. Thus, as a result of a detailed content analysis in the different communication channels and tools of the group, we address its impact on the team's agile project management (APM), adopted in a novel way by its members. Data compared between periods, once the strategic plan was co-created, suggest that this type of approach to co-created strategic thinking can improve coordination, cohesion and joint vision among participants. In agreement with emerging academic literature in this field, pertaining to the need to understand strategic planning as a process of socialization and dialogue, other relevant results of the study point to the particular suitability of this type of planning in research environments interested not only in its academic, but also social and ecosystemic impact. The results obtained and discussed also provide elements of assessment when considering the applicability of this type of strategic co-creation process in other areas of knowledge and disciplines.
\end{abstract}

\footnotetext{
${ }^{1}$ Austrian Centre for Digital Humanities, Austrian Academy of Sciences, Vienna, Austria. ${ }^{2}$ Internet Interdisciplinary Institute, Universitat Oberta de Catalunya, Barcelona, Spain. *email: enric.senabre@oeaw.ac.at; mfuster@uoc.edu
} 


\section{Introduction}

espite the current competition among academic institutions for resources and prestige in the adoption of evaluation systems, ranking mechanisms and performance indicators (Ordorika and Lloyd, 2015), regarding current challenges in the organisational dynamics of academic systems there's little evidence of successful strategies and practices for research project management (Derrick and Nickson, 2014). This is especially the case when it comes to the additional need to adapt the production of scientific knowledge to collaborative and interdisciplinary teamwork (Wuchty et al., 2007), connecting networked academic organisations and researchers (Wang and Hicks, 2015), in a new context that Jasanoff (2003) defined as the "participatory turn of science". From the fields of social studies of science and science of team science, authors like Jeffrey (2003) or Bozeman and Boardman (2014), describe how collaboration across teams and disciplines also requires progressive adaptation of a shared language and different types of tools. For these reasons, strategic planning seems to be one of the elements that could possibly contribute to better management practices in academia (Wilbon, 2012), which is usually a complex and everchanging process (Eccles et al., 2009). On the other hand, when considering alternative modes of knowledge production in academia, as well as the paradigmatic transition of universities in the global context (Santos, 2012), strategic thinking usually emerges in research groups oriented to achieve impact beyond the academic domain, like in the cases of action research (Fuster Morell, 2009) or mission-driven research (Holm et al., 2013). This article provides an analysis of how far co-creation could have a role in the application of strategic planning in academic contexts, in this case through an action research group, and its impact at the levels of management and interrelationships.

Strategic planning in the field of project management. With its foundations in the principles of action research and organisational development (Argyris and Schön, 1997), project management is generally considered as the practice of planning and executing the work of a team, based on specific control models and theories, to achieve specific goals and success criteria (Kerzner and Kerzner, 2017). From a social science perspective, however, project management has also been studied and applied in understanding projects as social processes, focusing on human behavior and actions within groups and organisations (Blomquist et al., 2010). Strategic planning, on the other hand, as applied in project management, can be defined as "deliberative, disciplined effort to produce fundamental decisions and actions that shape and guide what an organisation (or other entity) is, what it does, and why" (Bryson, 2011, pp. 4-5). Strategic planning, in this sense, is one of the most widely used strategy tools in business, but is also used in public and non-profit organisations (Ferlie and Ongaro, 2015).

Besides the fact that empirical evidence of a positive relationship between strategic planning and organisational performance remains inconclusive (Wolf and Floyd, 2017), after Mintzberg's (1994) critique of the fallacies of rational and centralized strategic planning as a top-down process, from the field of organisational studies it has also been analysed as a key mechanism for team integration and coordination, and as a basis for both centralizing and decentralizing organisational decision making (Spee and Jarzabkowski, 2011). In this regard, influenced by the mentioned social science perspectives, in recent years there has been a shift in the field of project management research on strategic planning (Wolf and Floyd, 2017), pointing to its benefits from the perspective of participative and socialized process models (Andersen, 2004). From this second perspective, strategic planning can be studied more as a "process" than a "product", and strategy development, therefore, as an evolutionary and integrative activity (Jarzabkowski and Spee, 2009), within a strategy-as-practice paradigm (Whittington, 1996). However, even considering how strategic planning has evolved towards these more integrated and process-oriented approaches, there has been little focus in management literature on addressing to what extent and, specifically, how it could be co-created using participatory methodologies.

State of the art on strategic planning applied to research. Again, with regard to the current challenges of academic systems and research activity from an organisational perspective, although there is scarce academic literature about strategic planning for research organisations, studies in this area show how it has gained some popularity in the general operation of universities (Srinivasa et al., 2015; Dooris et al., 2004), and also with open and participative approaches (Amrollahi and Rowlands, 2017). More specific studies about the application of strategic thinking in research examine its implementation in R\&D processes in firms (Bemelmans, 1979), in industry-academic collaboration (Burke et al., 1985), in research teams in the health sector (Leischow et al., 2008), in global initiatives of medical research (Berkley et al., 2010), in strategic collaboration within scientific centers (Boardman and Gray, 2010), or for the administrative management of research (Drummond, 2003).

In this respect, focusing on scholarly activity and academic organisations, relevant case studies on achieving collaborative and participative consensus for strategically planned research agendas address how to combine online tools and offline sessions during the process (Wilbon, 2012), or how to engage iteratively different academic communities of practice around research strategic planning (Best et al., 2015). Sá and Tamtik (2012), on the other hand, highlight the diversity of the approaches and perceptions of academics about the research mission, usually constrained by broader social and organisational structures of universities, and by the complex nature of the research enterprise itself. In all cases, however, there is still scarce literature on how to collaboratively develop strategic plans in academic research organisations, and its effect on group dynamics.

The co-creation approach: participatory design and agile project management. Co-creation (or co-production), which refers to processes of collective creativity, is a very broad term, with its applications ranging from the added value of customer participation in the definition of a product or service (Ranjan and Read, 2016), to public participation, collaborative governance or community involvement in civic-oriented projects (Voorberg et al., 2015). Within this broad concept, participatory design (or codesign) refers to a specific instance of co-creation that occurs when designers and people not trained in design work together in a design development process, with participants as "domain experts" of their own needs and experience (Visser et al., 2005). Some key principles of co-design, in this sense, connect with the perspective of iterative and participative strategic planning, as defined above, especially when it comes to the involvement of diverse stakeholders (Flood and Jackson, 1991). This points to the opportunity for adopting visualization techniques derived from co-design (Sanders and Stappers, 2008) in order to integrate different perspectives, mutual understanding, inspiration and engagement between participants in the research strategic thinking process (Eppler and Platts, 2009), thereby enhancing visual and textual representations of contexts and strategies (Giraudeau, 2008). 
On the other hand, some approaches analyse strategic planning from the perspective of how it can be improved by adapting agile project management (APM) (Cervone, 2014; Rand and Eckfeldt, 2004). APM, which can also be considered as a co-creation practice (Spinuzzi, 2015), consists of a set of methods and principles originally conceived for flexible and participative software development, but currently adopted in many other different domains (Ciric et al., 2018). This wider adoption of APM is due to its attributes of adaptive teamwork, transparency, continuous improvement and small and frequent releases for early delivery (Cao et al., 2009). APM, more so than other project management frameworks, emphasizes teamwork by focusing on the social aspects of project development, channelling co-creation between participants in self-organized, cross-functional teams (Hoda et al., 2013), with collective ownership and collective responsibility as key attributes (Robinson and Sharp, 2003). Among the different practices within APM, some typical ones are the regularity of short feedback meetings ("standups") and the use of kanban boards for visualizing the workflow and team tasks from conception to completion (Polk, 2011).

Research questions. The arguments exposed above justify the interest in an analysis connecting such diverse bodies of literature, in order to fill the gap and contribute to the questions about how strategic planning could be based on co-creation methodologies. And also, from a meta-research perspective (Ioannidis et al., 2015), how such an approach could be applied to research processes. More concretely, to what extent participatory design could be used for articulating the research planning phase, and afterwards integrated with the APM for the research development phase. This leads to the following two research questions, which form the basis of this study:

1. How can co-creation methods be used to lead the strategic planning process of a research group?

2. What would be the impact of co-created strategic planning on the agile project management of research?

Answering these two questions requires, in the first case, to describe in some detail how participatory design can be combined with strategic planning principles, explaining the integration of both approaches. In relation to the second question, a quantitative approach is needed considering the general lack of empirical evidence, especially in the fields of social studies of science and team science, on how strategic planning can impact research management. In this regard, our analysis of the cocreation approach to research strategic planning is applied to the participants, sequence and methods used in the entire process.

\section{Methodology}

In order to address the two research questions, a distinctive methodological design has been applied to each one of them. Articulated around a specific case study on the Dimmons research group, this methodological approach is twofold. The first part is based on participatory design, utilised to conceptualize and prototype the Dimmons strategic planning according to cocreation principles. The second part analyses the impact of cocreated strategic planning on the group's day-to-day APM, through content analysis of the online tools used for coordinating teamwork. On this basis, the results allow us to discuss which insights of the study could be generalized to current challenges in research project management.

Background of the Dimmons case study. Created in 2016, Dimmons (http://dimmons.net/) is one of the eleven research groups of the Internet Interdisciplinary Institute (IN3), the research center of the Universitat Oberta de Catalunya (UOC) based in Barcelona. Following the development of strategic planning of the IN $3^{1}$, which took place after the main strategic planning exercise of the $\mathrm{UOC}^{2}$ in 2016, the Dimmons group developed its own strategic planning with the aim of establishing its strategic objectives for the period 2018 to 2023. On the one hand, the selection of the Dimmons research group as a case study is due to how it is immersed in a strategic planning context that crosses several levels of the academic institution to which it belongs, reflecting an increasingly recurring but still little studied trend. On the other hand, Dimmons also represents a paradigmatic example due to its diversity, since it is composed of members with a consolidated scientific career, but also of $\mathrm{PhD}$ students, external collaborators and management-oriented profiles. Since the beginning of its activity, in that sense, Dimmons operates in a framework of competitive evolution between universities and research centers, and at the same time in new collaboration dynamics to achieve not only academic impact but also social impact, as we will see. In that sense, therefore, the case study reflects a way of addressing a series of current challenges and complexities that research groups experience between longterm strategic vision and day-to-day project management.

The Dimmons research group is focused on transdisciplinarity and action research for the study of socioeconomic innovation and the collaborative economy, from the perspectives of economic and public policy analysis. The group's composition since its beginning has evolved into a networked structure (Spinuzzi, 2015) which consists of different "layers" of participation (all of them involved with its strategic planning, as we will see in the results section). The action-oriented character of the research group, and its specialization in collaboration dynamics, makes it a case study particularly adapted to develop a novel approach, concretely in terms of opening up its strategic planning process by applying co-creation methods. This was seen early on as an opportunity to engage with its core team members and network of close collaborators, as well as with other representative stakeholders from the Dimmons community and ecosystem. In sum, the coincidence that the research group had to develop its own strategic planning, has an experimental and action-oriented approach, which added to its expertise on collaborative dynamics, made the Dimmons group a good case for the study. Regarding the first research question on how co-creation methods could be adapted for strategic planning, Dimmons was a good choice due to the group's regular adoption of participatory design techniques. On the other hand, Dimmons' novel adoption of APM (Senabre Hidalgo, 2018a) also favours addressing the second question, regarding the impact of the co-created strategic planning on the group's day-to-day management.

As a general result of the co-creation of the strategic plan, in which more than 40 people participated, there were a total of 38 actions defined in accordance with 6 strategic goals for the period 2018-2023, each one with an average of three key performance indicators (KPI) associated (97 in total). Its final version was published online on the Dimmons research group webpage. ${ }^{3}$ After one year of implementation, by the end of 2018, 24 of the 97 KPIs were accomplished satisfactorily. This result represents an accomplishment of $24 \%$, and considering that a 5 -year period is envisaged for full implementation of the plan, suggests satisfactory performance in terms of achieving the co-defined goals during the first year.

Participatory design for how to apply co-creation in strategic planning. Regarding the first research question ("How can cocreation methods to be used in leading strategic planning process of a research group?") the methodological approach was 
qualitative, based on participatory design. Departing from the key consideration that participatory design is indeed a methodology of action research (Spinuzzi, 2005), and benefiting from cocreation derived from design thinking methodologies (Kimbell, 2012), which have proven to improve participant engagement in research (Senabre Hidalgo et al., 2018), we established different visual and discussion techniques at each stage of the process for the effective participation in a transdisciplinary context. The participatory design was developed and data collected from the fall of 2016 through 2018. The methodology applied is consistent with the participatory design notions of user-centered co-creation, in detailed stages and techniques such as those described by Naranjo-Bock (2012) for (1) self-reflection of research methods (focusing on research goals and questions, who the participants are and what tools they can use, the stage of the project, etc.); (2) running co-design activities onsite, with techniques and "placements" like context mapping, storyboards, inspiration cards, diagrams or paper prototyping; (3) pilot testing and results, where the data obtained is generally visual and tangible, accompanied by the important debrief of the results of each participatory design session or process.

Following that approach, and adopting the framework of Spinuzzi (2005), through different qualitative techniques the cocreation process was structured around the three key phases of: (1) Initial exploration of work, where participants meet each other and commonalities are identified, as well as for preliminary discussions; (2) Discovery processes, when design facilitators employ various techniques to understand and prioritize work organisation, clarifying the participant's goals and values; and (3) Prototyping, a final stage for iteratively shaping outputs and assessing results. The data came from a range of sources, including offline co-creation sessions and team meetings, meetings and interviews with some researchers and collaborators, as well as documentation resulting from the different phases and sessions of the strategic planning. Outputs of each participatory design stage were recorded in detail as they took place, through documents shared online.

Content analysis for the impact of a co-created strategic planning on APM of research. Regarding the second question ("What would be the impact of co-created strategic planning on the agile project management of research?"), the approach was based on quantitative data collection and text analysis, in order to address how far the co-creation methodologies had an impact on the group's project management, focusing on the researchers' discussions and behavior through digital channels. The analysis was based on extensive content analysis of two of the main online coordination tools for the AMP of the group: a chat group for daily communication and an online kanban board platform for task management.

Telegram chat content analysis. The "Dimmons al dia" Telegram chat group was adopted from February 2016 until the end of 2018 as a first approach to daily standup meetings, inspired by the Scrum method derived from APM for software development (Cervone, 2011). Scrum, which is one of the most adopted agile frameworks for managing knowledge work, facilitates the coordinated activity of participants who break their work into small tasks that can be completed within fixed duration cycles or "sprints", tracking progress and re-planning in regular meetings in order to develop projects incrementally (Senabre Hidalgo, 2019). Via Telegram, on a daily basis from Monday to Friday each Dimmons team member (a total of 15 users, through different periods over time), via a short message during the morning period, informed others about the planned tasks for the day (Fig. 1), among other coordination discussions that took place regularly on that chat tool between team members.

A combination of computer-assisted massive text analysis and comparative visualizations ${ }^{4}$ for these chat discussions on the Dimmons Telegram group was used, after dumping and extracting to plain text the full history of the "Dimmons al dia" chat group since its creation (a text corpus mainly in Catalan, which is the normal language of team members). The data gathered consisted of the complete history of messages from 2 September 2016 to 27 December 2018 (28 months of activity). This represented a corpus of 6520 messages, with a size of 794,464 characters in 6941 lines of text.

Afterwards, in order to compare the different flows of communication in relation to the co-designed strategic plan of the research group, it was decided that the date on which the first strategic planning team workshop took place (20 December 2017) would be used as the key date for dividing the chat history in two plain text documents: "Xat Telegram Dimmons al dia 2017" (prestrategic plan period, until 20 December 2017, with 78,644 total words) and "Xat Telegram Dimmons al dia 2018" (post-strategic plan period, after 20 December 2017, with 83,200 total words).

As a first step in the analysis, prior to coding, the plain text obtained from each document was processed as a tabular view of terms frequently used in the entire corpus. That is, a list of the most used terms for the period 2017 and a list of the most used terms for the period 2018. This facilitated an initial overview of recurrent terms, which could then be filtered and coded, identifying multiple stop words to exclude (non-relevant meaning, numbers, ambiguous terms, etc.) and on the other hand selecting specific words related to categories to include in the analysis. The coding of data obtained in this way consisted of the clustering of words relevant to the following two categories:

1. Coordination-related terms: data about terms related to time periods or days (today, tomorrow, now, etc.), general work-related keywords (meeting, call, document, task, pending, etc.), as well as specific verbs (preparing, sending, finishing, etc.).

2. Strategy-related terms: data about terms related to the six main goals of the Dimmons strategic plan (as described in the results section), for (1) academic impact (paper, data, review, survey, specific projects, etc.); (2) open tools (platform or toolkit-related); (3) ecosystem (specific partners mentioned, dissemination or projects); (4) team care and empowerment (words related to good climate among members, greetings, gender topics, etc.); (5) sustainability (new proposals, specific projects for new funding); and (6) university shift (references to the university or research center).

Kanban board content analysis. In January 2017 (when the strategic planning was co-designed) the Dimmons team adopted an open source project management software (https://kanboard.org/) for additional APM practice, such as the use of an online kanban board for visualizing the flow of tasks accomplished by core team members (Fig. 2).

For this, in connection with the six strategic goals defined in the co-design phase, each planned task could be properly tagged (selecting "academic impact", "open tools", etc.) according to the researchers criteria. In addition, tasks could be classified by selecting from a dropdown menu the corresponding project or category (specific projects, management tasks, dissemination, publications, events or initiatives related to networking, etc.). An analysis of this workflow-related data on the Dimmons online kanban board during the mentioned period (with different levels of participation among the nine core team members, depending 


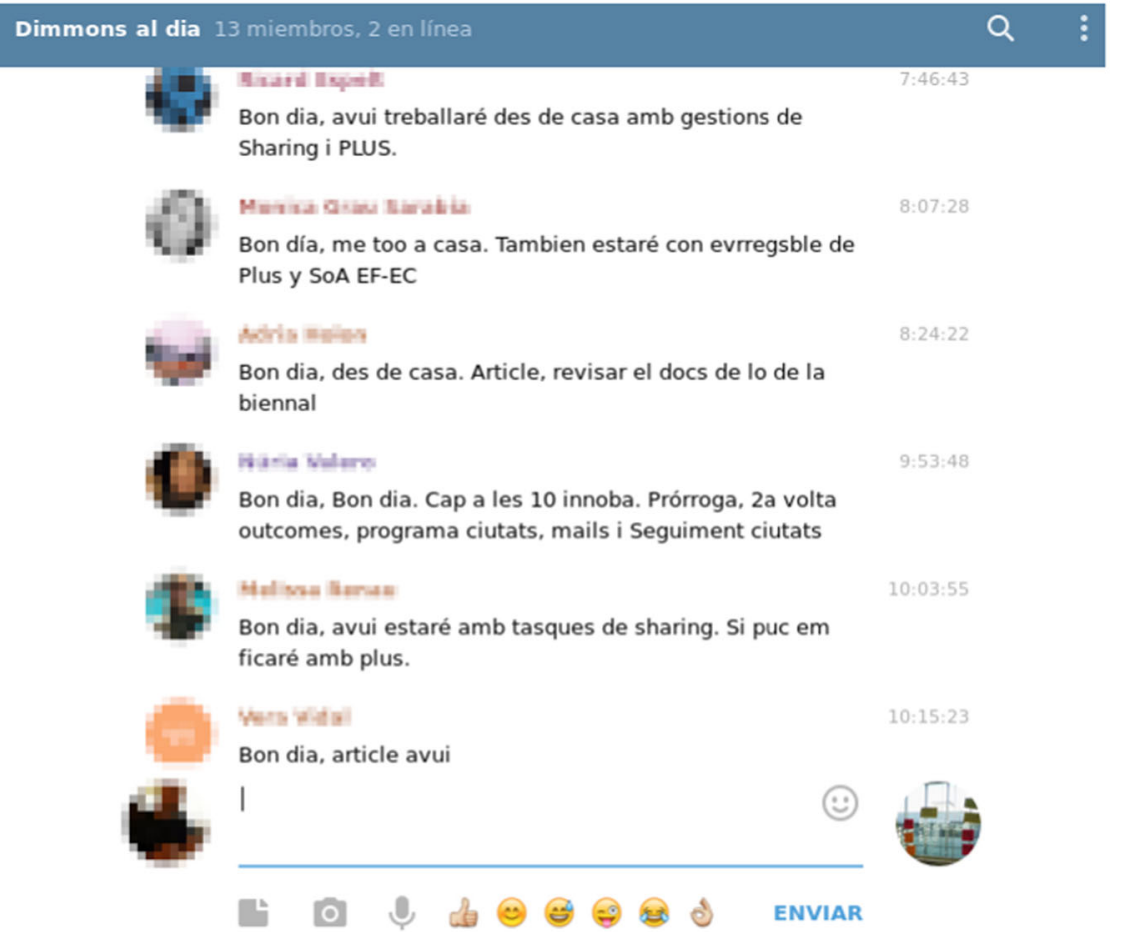

Fig. 1 Screenshot of the Telegram chat group for daily updates about tasks.

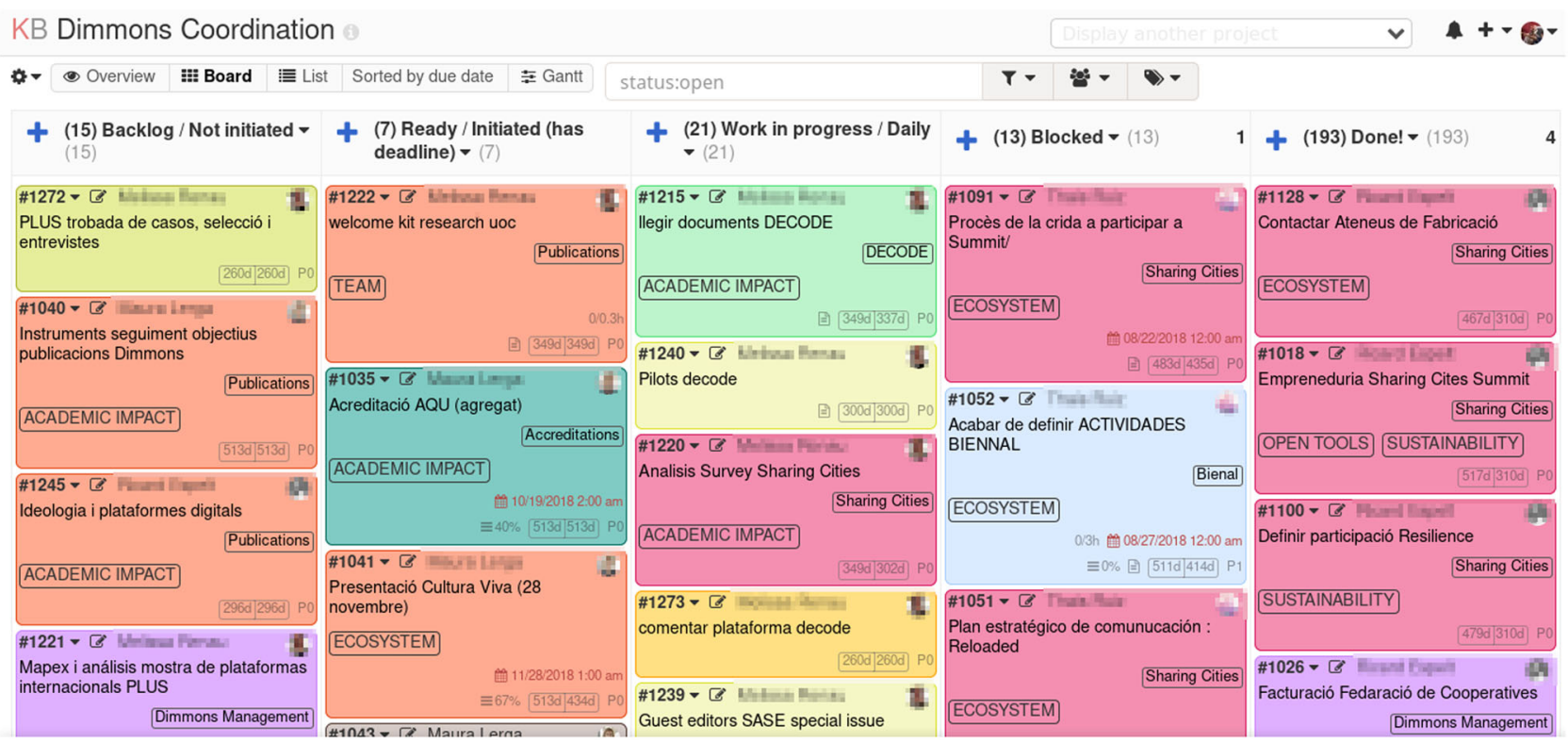

Fig. 2 Kanban board reflecting the workflow of tasks of team members, related to strategic goals and specific projects.

on their familiarity with digital tools and perception of utility) allows for an understanding of the evolution of planned and achieved tasks in relation to the Dimmons strategic plan, as well as among team members.

Data obtained from the Kanboard log comprised details about a total of 166 user-defined tasks, in relation to tags selected (for the six strategic goals), category of project selected (among the 11 existing projects and initiatives during 2018), user activity, level of accomplishment, due dates and task description, among others. In this case, the coding related to the strategic goals was self-generated by each user at the moment of naming and defining the task, by selecting the most appropriate tag in relation to the strategic goals.

\section{Results}

This results section is divided into two parts, which address the research questions with the methodologies described above. First, we outline how the co-design process of the Dimmons research group planning unfolded, describing the methods used, as well as its internal and management implications, based on the participatory design process itself. Secondly, we summarise the main results of the impact of the process on the group's project management and regular communication in relation to its experimental co-creation approach, derived from the content analysis of the main coordination channels used during the regular activity of Dimmons. 
How can co-creation techniques and principles be used in leading the strategic planning process of a research group? Insights from the participatory design of the Dimmons strategic planning. In relation to the first research question, about how can the strategic planning process of a research group can adopt co-creation methods, the participatory design practices and principles adopted resulted in an iterative, dialogic and eminently visual approach to strategic planning. Questions related to participants ("who"), sequence ("when") and methods ("how") were of critical importance since the beginning of the process (Table 1).

"Who": Participation as ecosystem. In contrast to the traditional strategic planning process, developed by the group's core team only (i.e., those with strong ties to it), Dimmons adopted a broader perspective in which the basic principle for co-creation that emerged was the concept of "participation as ecosystem" (Fuster Morell, 2010a). That is, the Dimmons research group could be considered a research ecosystem with diverse forms and degrees of involvement, following the structure of a "power law dynamic" (or "1/9/90") in online collaborative production (Fuster Morell, 2010b). This reflects the composition of the participation that took place when articulating the strategic planning process, according to the three layers of the Dimmons research ecosystem:

1. Core Team: Director, postdocs and PhDs with grants, and research assistants (9 people).

2. Dimmons "Community": University professors, former visitors, external researchers, experts and practitioners on Dimmons areas (12 people).

3. Dimmons "Ecosystem": Representatives of a network of institutions with further collaborative relations, target impact or audience (10 participants from a total of 32 private and public organisations).

In relation to this, a first observation regarding how to apply cocreation in strategic planning has to do with the suitability of adopting a broad, open and participative approach, as well as decentralised approaches for higher engagement and performance in dynamic environments (Andersen, 2004). For this reason, who to involve in the process became a critical aspect, considering that ecosystemic participation is also meant to engage the research group community and stakeholders in the process (not only highly involved team members). In this case, the open invitation to all members of each layer of the ecosystem, as defined above, resulted in the "power law" distribution, of which only a small representation were engaged in the process but with a high level of involvement through the different co-creation sessions. Defined as a modular sequence, with the possibility of joining the process at different times, also allowed for a wider participation than if following a rigid and traditional strategic planning approach.

"When": Iterative sequences of convergence and divergence. The iterative unfolding of the co-creation process was another main characteristic. That is, rather than a predefined sequence of steps, the guiding principles were based on the participatory design notions of "convergence" and "divergence" (Sanders et al., 2010). This allowed for several divergence instances (during which a considerable number of possibilities regarding goals, ideas, SWOT factors ${ }^{5}$, etc. were generated by participants), followed by intense convergence stages of synthesis (where the main options were presented, discussed and finally selected via different mechanisms).

Departing from that key consideration in co-creation, and its adaptation of a sequence guided by participatory design methods (Spinuzzi, 2005; Sanders and Stappers, 2008), the overall approach of the participatory design integrated key notions in literature for effective strategic planning (Wilson, 1994). In this respect, the organic and iterative development of the process as a co-creation sequence was consistent with the four stages of a strategic plan, as defined by Eppler and Platts (2009): analysis, development, planning and implementation (Fig. 3).

As reflected above, a key consideration derived from the case study in relation to its temporal sequence is that it was possible to establish a clear coherence between the literature of co-creation and participatory design (Spinuzzi, 2005; Sanders et al., 2010; Spinuzzi, 2015) and of visualization techniques for strategic planning (Eppler and Platts, 2009; Eppler et al., 2006).

Table 1 Key questions for co-created strategic planning in the Dimmons case study.

\section{Participants (who)}

- Participation as ecosystem

- Power law dynamic (1/9/90)

- Decentralised
Sequence (when)

- Iterative

- Convergence and divergence stages

- Organic

\section{Methods (how)}

- Initial exploration of work

- Discovery processes

- Prototyping

- APM
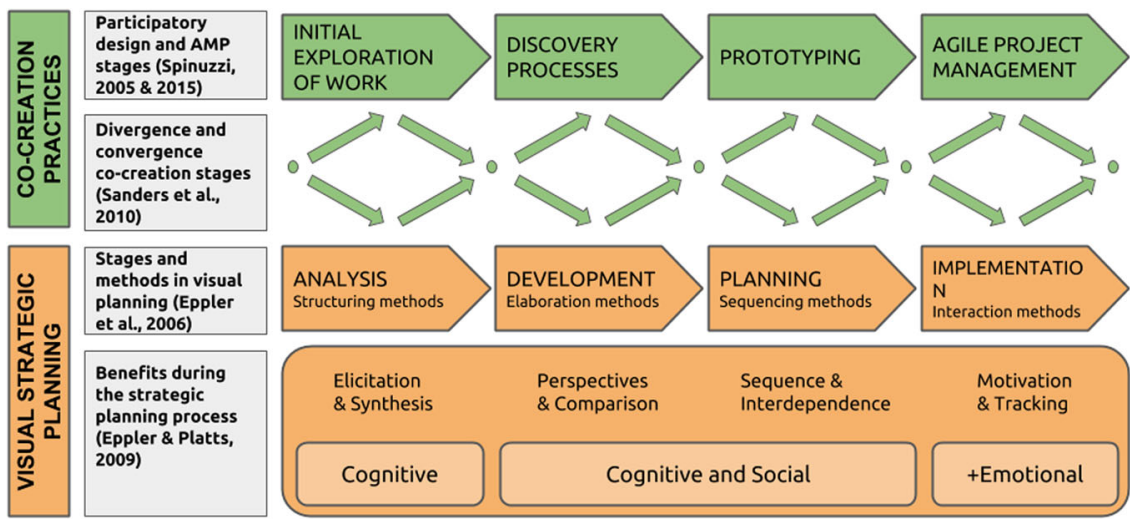

Fig. 3 Stages followed in the co-creation of the strategic plan of the research group, connecting co-creation approaches (Spinuzzi, 2005; Sanders et al., 2010; Spinuzzi, 2015) with visual strategic planning (Eppler et al., 2006; Eppler and Platts, 2009). 
"How": Integrating ${ }^{\circ}$ co-creation methods in strategic planning. The co-creation process unfolded by connecting the different participatory design stages to specific phases of strategic planning, via a combination of five sessions in total and the adoption of nine co-creation methods (in offline but also online formats), and with the regular participation of diverse participants from the Dimmons research ecosystem (Table 2).

In this way, the first co-creation workshop (Fig. 4) focused on mapping personal attitudes and strengths, experience in methods and research approaches, which contributed to visualizing methodological affinities within the group.

Following the mentioned co-creation principles of "convergence" and "divergence" (Sanders et al., 2010), the second cocreation workshop departed from the first survey results to engage in a broader discussion about the mission and guiding principles of the group, which were discussed and re-edited offline during the debate. That second session also adopted a card-sorting technique for clustering the survey results of the SWOT. During the second co-creation workshop, a first version of the map of the Dimmons ecosystem was also drafted and discussed. An important part of this participative analysis stage of the planning was the collective identification of the "ecosystem" or external environment in which the group operates. For this, a key activity was the collective mapping of the different institutions and agents with which Dimmons collaborates or has a relevant relationship, bringing the concept of ecosystemic research closer to the perspective of the Quadruple Helix for innovation systems (Carayannis and Campbell, 2012). In contributing to the generation of an internal environment of transparency and openness, it is important to consider that all the dynamics took place in a context of action research where the majority of participants were familiar beforehand with similar methodologies and processes to integrate diversity and explicit points of view. Also noteworthy is the general absence of conflict situations during the whole process, and that initial discussions about methodologies and specific theoretical perspectives were activated early on. This was probably due to the fact that it was based on a small core of participants who were already cohesive around the Dimmons team, joined by other actors with diverse theoretical backgrounds and experience, and for that reason each session was oriented towards the search for synergies and learnings, making explicit the knowledge, expectations and opinions of the majority of the group. However, it should also be pointed out that sometimes during the discussion, the opinion of those with a consolidated academic profile tended to weigh more and took more preeminence, in contrast to predoctoral researchers or participants with a profile not linked to academic research.
As another important element of the group's strategic thinking in this case, the final stages of the process not only had as benchmark reference the IN3 research center's strategic goals, but also the potential connection with the Sustainable Development Goals (SDG) and Responsible Research and Innovation (RRI) principles. The SDGs are a collection of 17 global goals set by the United Nations for addressing urgent issues like poverty, education, gender equality, energy, environment or social justice, among others (Griggs et al., 2013). RRI is a multidisciplinary approach promoting the involvement of stakeholders and civil society in scientific activities for developing more inclusive innovation processes (Owen et al., 2012). This element of strategic planning around external indicators represented for all participants a first approach to new principles and a series of values, leveraging perspectives and discussions around the key aspect of social impact of research beyond the academic context.

As a final result, among the different key elements that are usually integrated into a strategic plan (Eppler and Platts, 2009), the definition of six strategic goals were incorporated into the first draft of the document (considered as a "prototype") of six strategic goals: (1) Academic impact ("generate a high-quality research corpus of theoretical framework on socio-economic innovation"); (2) Open tools ("contribute to processes in action for the resolution of social challenges by developing researchbased resources"); (3) Ecosystem building ("consolidate a 'glocal' network of partner organisations for quadruple helix collaboration to favour social impact and resilience"); (4) Empowered team ("consolidate the team with complementary backgrounds, healthy environment and gender-balanced talent"); (5) Catalytic sustainability ("obtain funding for action research from competitive calls with high impact and visibility"); and (6) University shift ("engage with open access, "commonification" processes, transdisciplinarity, agile principles and other changing paradigms in the academic culture").

What would be the influence of co-created strategic planning on the agile project management of research? Insights from the analysis of impact in Dimmons coordination. Once the strategic plan was finished and shared online as a definitive version, it was incorporated into the day-to-day activities of the research group, both explicitly (by incorporating the strategic goals as categories in the group's agile kanban board for task management) and implicitly (by guiding topics of conversation, and being in the background when regularly communicating online and offline). In order to analyse it and answer the second research question of this study, on what would be the influence of a co-created strategic planning on the APM of research, a series of content analysis on the main coordination digital channels provides different

Table 2 Dimmons strategic planning according to participatory design stages, methods, format and number of participants.

\section{Participatory design stage}

(Spinuzzi, 2005)

Initial exploration of work

Discovery processes

Prototyping

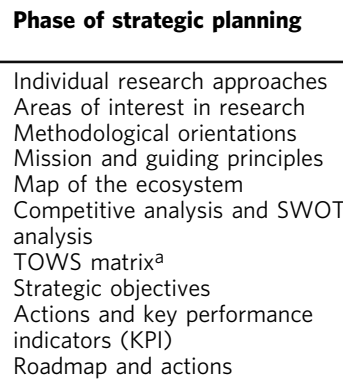

Co-creation method

\section{DIY accreditations}

Lightning talks + Concept clustering Dotmocracy

Survey \#1+ Shared document

Survey \#1+ Diagram

Survey \#1+ Card clustering

Shared document

Brainstorming + Shared document

Shared document + Survey \#2 (for

priorisation and validation)

Shared document

\section{Meeting format \\ Participants}

\section{Offline session}

Offline session and Online

Offline session

Offline session and Online

Offline session and Online

Offline session and Online

Internal meeting and online

Online

Offline session and Online

Offline session

\section{First co-creation workshop: Core team + Community members (16 participants) Second co-creation workshop: Core team + Community members (10 participants) \\ Core team (4 participants) \\ Core team + Community members (10 participants) Core team (4 participants)}

aWhile the SWOT analysis focuses on opportunities and threats at external and internal levels, the TOWS matrix is a technique for strategy generation and selection, opted at the later part of the planning process to decide the way forward 

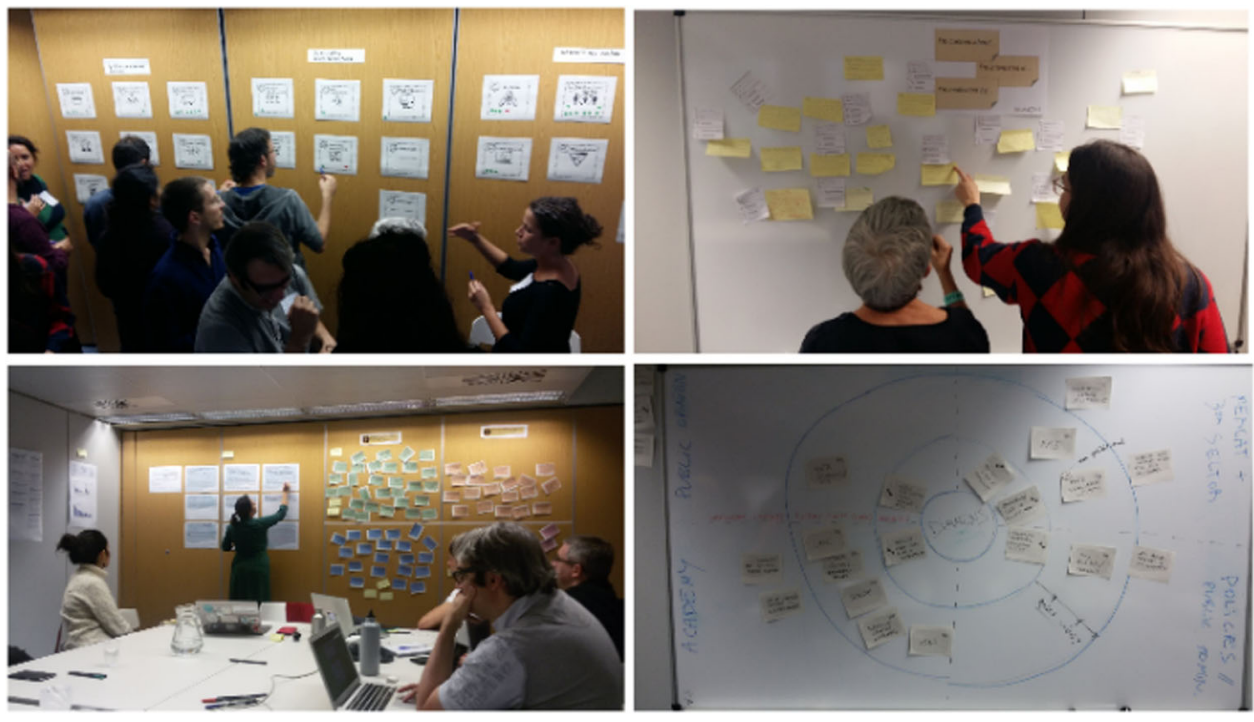

Fig. 4 Different moments and materials used for the workshop sessions with the research team.

elements for discussion, especially from an action research perspective.

Dimmons Telegram chat content analysis. The evolution of user's daily participation on the Telegram chat during 2017 and 2018 suggests that once the strategic planning was co-designed and adopted (at the end of 2017), the communication dynamics evolved from being relatively asymmetric (with just a few very active users) to a much more balanced distribution where all members contributed, following the "standup" meetings and derived conversations (Fig. 5).

More specifically, from a medium used by nine participants over a timeframe of approximately two years, the co-design and implementation of the Dimmons strategic plan between December 2017 and January 2018 seems to set a landmark between a relatively unequal distribution of messages among team members (where only a few of them contributed, at very different levels) to a regular pace and volume of interventions by the majority of participants. This probably derived from applying the strategic planning as a co-creation sequence, thereby as an integrative and socialization process. In this sense, it should be noted that among the observations about the daily communication of the group through the Telegram channel, most messages and discussions focused on the planning and execution of tasks, both academic (writing articles, organisation of workshops, data collection, etc.) as administrative (agenda management, budgeting, event logistics, etc.). In contrast, during the day-to-day of the group and outside of the co-creation process itself, theoretical or conceptual discussions normally took place in other spaces and moments, normally during the development of face-to-face meetings between two or more members of the group (before and after the strategic planning process).

On the other hand, if we look at data from the content analysis of the daily update "standup" messages in 2017 (again, prior to the strategic plan) compared to the corpus of terms used in 2018 (once the strategic planning was in place) patterns also demonstrate a coincidence with a significative increase of terms related to the different strategic goals, and therefore a probable influence of the strategic planning on the daily communication of the group (Fig. 6).

This reflects a relative imbalance in how the different goals were addressed during both periods. While, according to these results, the attention to the group's ecosystem and to academic impact where at the center of activity, there was much less activity, in terms of percentage, related to others such as the generation of open tools or team care. This imbalance simply demonstrates that after year one, of the five goals covered by the strategic plan, the group gave priority to tasks and processes related to its ecosystem (specific partners, collaborators or events), as well as pertaining to academic impact (publications, data, surveys, specific projects under development). What seems significant from this data, apart from how it can serve as a parallel indicator to the group's agreed KPIs, is the increment and diversity of terms related to the strategic plan in the regular conversations and update messages on the Telegram chat for the 2018 period (and to what extent they were more relevant than in the previous year, before the co-design of the strategic plan took place).

In relation to the adoption of APM methods (in this case, establishing additional regular weekly meetings and the use of a digital kanban board, beyond the daily updates via Telegram), the increment there between 2017 and 2018 in vocabulary related to coordination tasks, timing and other key terms is also significative. Specially the preeminence of messages containing words like "today", "pending", "version", "tasks" or "meeting", which doubled in general compared to 2017.

Again, patterns show a wider use of vocabulary in coordination-related communications, with reference to tasks informed on a daily basis, once the co-creation process around the strategic planning of the research group took place. This suggests not only that team communication incorporated more perspectives related to the Dimmons strategic goals, as observed above, but also more references to general coordination and therefore the operative awareness of the group.

Finally, if we focus on 2018 (the period of the co-designed strategic plan), another relevant analysis of the content data gathered via the daily updates and conversations on the Telegram group chat, is the extent to which it reflects a very similar proportion of conversations about specific areas of the strategic goals (Fig. 7) for the tasks defined on the kanban board. In both cases, the majority of references during 2018, coincidentally, focus on academic impact and ecosystem building, followed by a corpus of team-related and university shift terms.

Dimmons kanban board content analysis. "As mentioned above, the results of the tags used most on the kanban board related to the strategic goals, when informing the regular tasks of team 


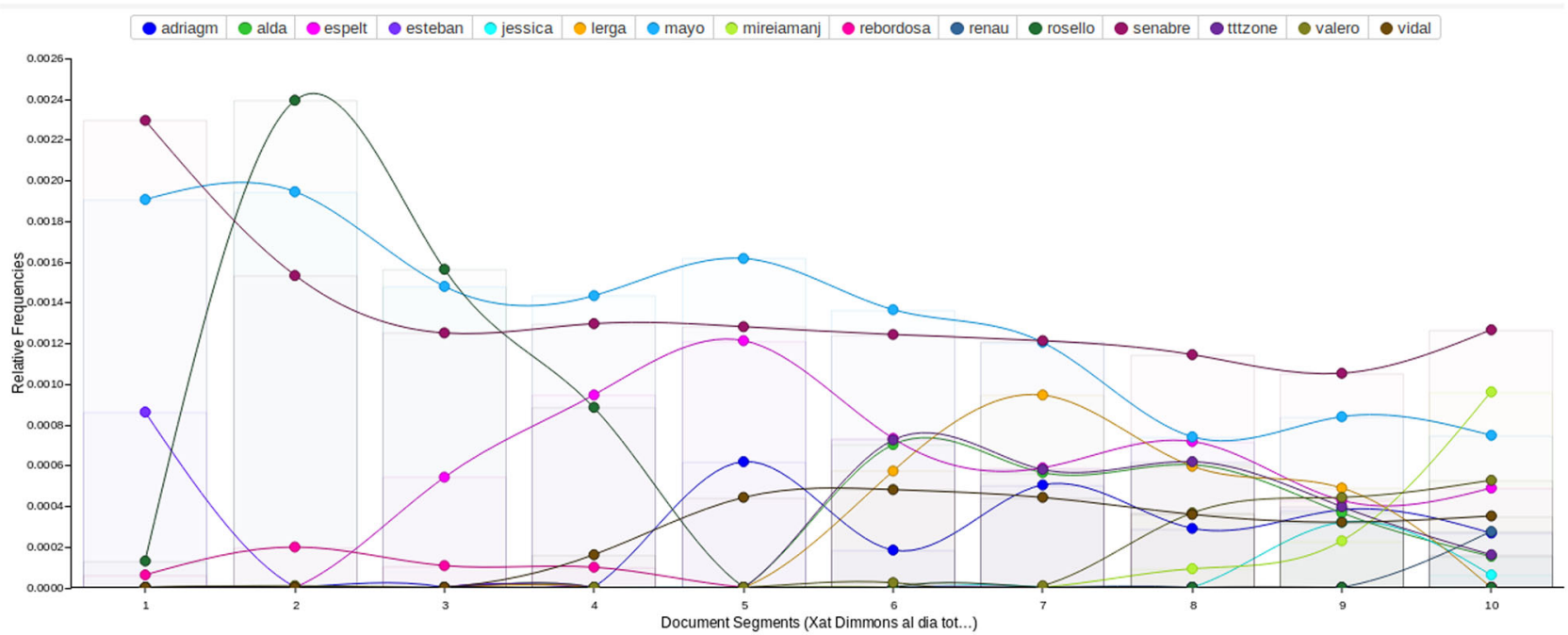

Fig. 5 Evolution of user participation in "Dimmons al dia" Telegram group chat during 2017 and 2018.

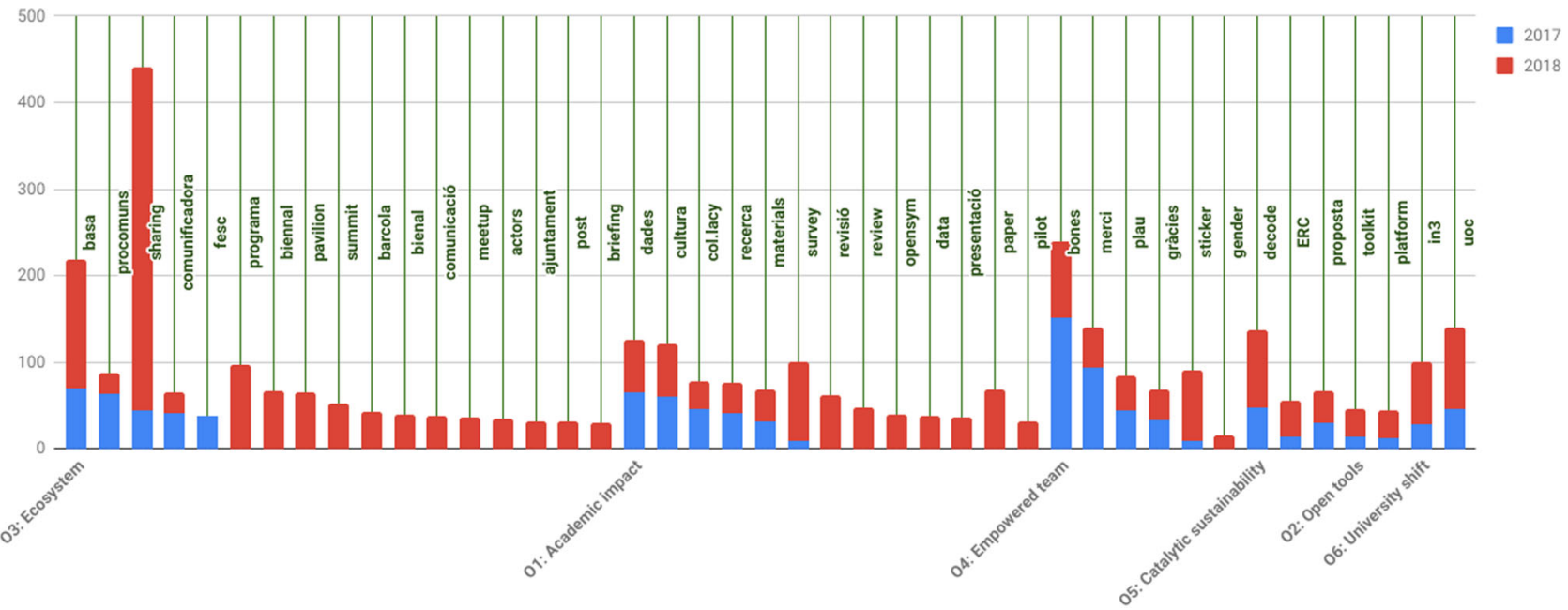

Fig. 6 Comparison of mentions to Dimmons strategic plan related terms in Telegram between 2017-2018.

members, point to a very similar distribution as in the previous analysis of the Dimmons main Telegram chat, where academic impact and ecosystem creation are the most selected ones, followed by a smaller proportion of the other four categories".

This suggests that both patterns coincide as an indicator of the most influencing priorities for the team derived from the strategic plan, but more importantly points to a coherence on a shared vision as an action research group derived from the co-design process. Also, this result when comparing content on the coordination channels, suggests a consistent integration of the strategic goals with the APM methods, ensuring an interconnection between the strategic plan goals and the daily activities.

Another result from the task-related data gathered via the kanban board is to what extent there's a good balance of members contributions to the projects and initiatives connected to the strategic goals. Instead of a specialization pattern or "monolithic" distribution of projects to researchers, despite the different levels of participation informing planned tasks between users, results show a relevant quality of teamwork in terms of shared projects and cross-functionality.
In addition, the extent to which specific projects not only comprehended tasks related to different researchers but also to the various strategic goals, suggests a coherent and transversal categorization when researchers classified their regular activity in relation to the strategic plan. Data obtained from activity on the kanban board, when compared with activity on the Telegram chat informing about planned tasks for each day, also shows a clear correlation between the content generated in both channels and terms related to the different strategic goals. As already indicated, however, not all the core team members used the kanban board with the same level of regularity (as opposed to the Telegram daily updates, where participation followed the same volume and pace for all team members), with the main reason probably related to the difference in the levels of familiarity with digital tools for management.

\section{Discussion}

With this study a prototype and analysis of a co-creation methodology for the strategic planning process of an action research 


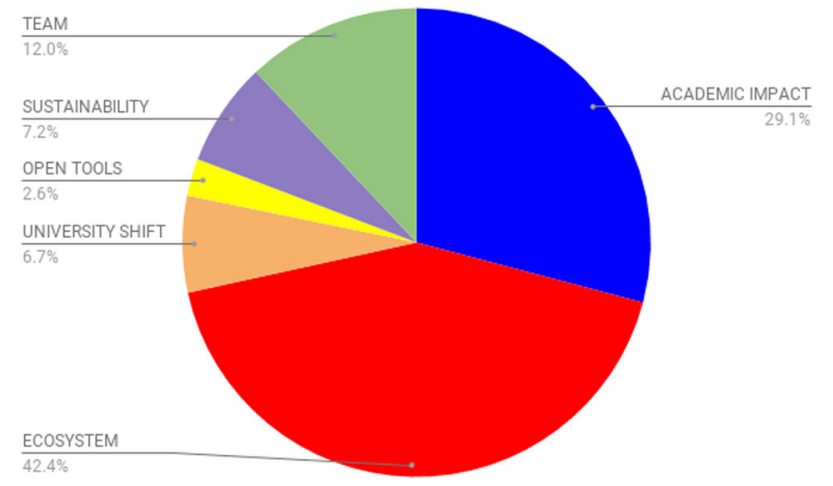

Fig. 7 Percentage of terms related to Dimmons strategic goals on Telegram chat during 2018.

group was developed. Regarding participation, guided by a 'strategy-as-practice' approach in project management and the concept of ecosystemic research, the case study integrated the diversity of perspectives and voices of more than 20 participants in total. This way of proceeding generated a key mechanism for team integration and coordination within the group, and also with its external layers of collaborators and stakeholders, which were also represented through the process. As data indicate, this required a combined approach of co-creation methods and iterations, which followed principles of participatory design and online participation. As a consequence, besides a fully defined document for the strategic roadmap of the group activity, the different actions co-defined by the core team and its ecosystem of collaborators achieved a satisfactory level of accomplishment after the first year of implementation.

In relation to the first research question, on how co-creation methods can lead the strategic planning of a research group, our study points to the possibility of developing strategic planning processes with such methods. In this respect, our contribution reflects the key methodological aspect of integrating participatory design techniques for structuring the process. This aligns with theories connecting principles of action research in social sciences, and especially co-design in the context of organisational learning, in terms of tacit and explicit knowledge transfer processes, as well as constructivist approaches to addressing complexity and uncertainty in teamwork (Argyris and Schön, 1989). The analysed case study of Dimmons, in this sense, seems coherent with a wider consideration of design thinking as a practical approach for enabling transdisciplinary collaboration and as a process for "shaping processes" (Lindberg et al., 2010). In our opinion, as addressed in this case, this connects to the need to adapt strategic planning to co-creation practices as a decentralized, integrative and iterative dialogue (Wolf and Floyd, 2017). Our analysis also suggests the opportunity for the utilization of academic strategic planning as a means of integrating the values of the social impact of research, such as those derived ones from SGD and RRI, which can be adopted as a landmark when addressing academic and scientific activity from a collaborative and ecosystemic perspective. Observations and outputs from this process reflect that it allowed for deeper insight into discussions and comparisons about research methods, in many cases for the first time among team members. By "voting" for preferences and visualizing expertise in such explicit ways, and selecting a wide range of possible methods, the iteration and parallel discussion allowed for the identification (later on the strategic planning process) of several areas of improvement and implications for the group composition in the mid and long term. All the data generated and shared as open documentation during this first initial exploration stage of the strategic planning, concerning the group's composition, allowed on the one hand, the identification and mapping of opinions, basic assumptions and implicit understandings around research that needed to be surfaced, and on the other one the initiation of the co-creation of the strategic planning with the needed openness and implication of all participants.

Regarding the applicability of the model to managing research projects in other scientific research contexts, the type of participatory co-design described and the degree of involvement of the different layers of stakeholders probably require departing from reduced, cohesive teams and familiarity with principles of action research or community-based research, frequent in the social sciences. In this sense, it is important to highlight that, as detailed in the first part of the study, the concept of impact of research was regularly taken into account beyond the academic context, as a requisite to integrating in the strategic planning other perspectives that do not come from the scholarly context. As another relevant element derived from the results of the study, when prototyping the co-design process in connection with previous research on visual strategic planning (Eppler et al., 2006; Eppler and Platts, 2009), it should be noted that the iterative sequences of convergence and divergence of each phase allowed the described levels of participation and integration of perspectives. Again, considering it a strategic thinking process that is likely to be generalizable in research contexts in which, beyond academic and administrative tasks, there are conditions for the consideration of different types of research impact for initiatives in the medium and long term.

Regarding the second research question, the results pertaining to the impact of the co-created strategic planning on the group's APM coordination and communication routines (and specifically data about terms related to the strategic plan) suggest that it contributed significantly to a shared vision and helped to deal with the inherent complexity of research activity (Fuster Morell, 2012). In this sense, with respect to the positive influence of a cocreated strategic planning on the APM of research, our method provided results complementing previous studies (Rand and Eckfeldt, 2004). Specifically, we described how the integration of strategic goals with the agile management of daily tasks can serve as a parallel indicator to KPI used in strategic planning, and how such integration can provide immediate user-generated information for assessing the implementation of the plan (as compared to the usual retrospective checking of KPI over longer periods of time). Taking into account the need to connect strategic plans with managerial practices during the implementation phase (Poister, 2010), this combination of co-design techniques and AMP practices for the strategic planning of the Dimmons research group reflected the importance of design features and social mechanisms for successful strategic planning (Barzelay and Jacobsen, 2009). The data compared between the period prior to the strategic plan and its co-creation process suggest, on the one hand, an increase in the group's cohesion through its daily communication and coordination channels, and on the other, an alignment in terms of discourse and follow-up of the objectives set. Again, in relation to being able to extrapolate the results of this process to other contexts, it is probably key to start with some previous experience with basic principles and practices of project management, and especially those based on AMP. However, as we reflect in the first part of the study, on the state of the art in social studies of science and team science with respect to the management of research projects, as well as the progressive need for mechanisms of efficiency and collaboration in academia, it is likely that this type of approach could be useful and produce similar results in other types of scientific and research initiatives.

Despite the above, the results also show a relevant imbalance between the accomplishment of some of the strategic goals after the first year of implementation of the strategic planning, with a 
significant dedication of efforts to "ecosystemic activity". This suggests that, from an action research perspective, after the participative design process there was a greater priority given to the perceived need for addressing tasks related to community events, meetings with stakeholders, institutional agreements or online dissemination. In contrast, according to the data derived from the combination of KPI compared with the volume of specific tasks defined in the APM coordination channels, critical aspects of research management related to team building or open tools did not receive as much attention and effort in comparison. In our view, besides the experimental character of the case study (and the novelty of its research group focus), this result also relates to the current context of pressure and complexity within "accelerated" academic organisations (Vostal, 2016), which represents a challenge in front of competition for excellence (Sørensen et al., 2016) and the "projectification" of university research (Fowler et al., 2015). In this sense, in relation to the day-to-day activity of the group connecting strategic planning with co-creation principles of APM in research, it was observed that the experience also increased the need for the project management role or main facilitator of the entire cocreation process. In this regard, it was usually complicated to separate that function, as the guide of the participatory design of the strategic plan, from the wider role of APM coordinator.

This study's limitations and potential mainly have to do with two areas. On the one hand, the content analysis of the kanban board covered an early stage of its adoption, but in comparison to the Telegram chat activity not all participants used the system with the same level of intensity and engagement. As explained in the results section, however, the relative coincidence with percentages of strategic-related terms between both channels suggests it worked as a relevant source of data for assessing the implementation of the strategic plan. In relation to the co-creation process, this limitation (related to an unequal adoption of APM coordination by the majority of the group), represented a challenge for some participants, and probably affected its impact during the implementation stage of some of the strategic goals. As mentioned, the degree of familiarity with digital tools for project coordination, as well as with internal discussion processes and personal positioning in research projects, seems a key factor that also requires future analysis in other academic contexts, to determine to what extent similar processes of co-creation and strategic thinking can be applied in the field of social sciences and in other disciplines. On the other hand, following this type of exploratory analysis, the need to observe and compare data generated by other research groups that apply similar (or different) methods for project management and strategic planning creates in our opinion a potential for future research, and would allow for further understanding of such an important area of meta-research. In this line, another analysis based on the case study of the Dimmons research group for a different period in the near future, in order to compare the evolution of KPI in parallel to communication and coordination related to tasks until 2023, would be needed to confirm some of our initial results.

Through this study we have described how strategic planning could be applied to research in order to confront current challenges in academic collaboration, and how to do so through the opportunities offered by co-creation methodologies applied to project management. Our analysis has identified potential benefits and challenges in this respect, suggesting further development of this field in the social sciences and action research, and proposing it as a possible area of research and development in parallel to other documented and studied efforts to deal with innovative and agile management of scholarly work. Besides an analysis of its impact at the communication and relational levels, our study also offers a detailed description about how co-creation for strategic planning in research could be applied, which could be of practical interest for scientific institutions in relation to their project management practices.

\section{Data availability}

Due to privacy reasons, the datasets analysed during the current study are not publicly available but are available from the corresponding author on reasonable request.

Received: 6 April 2019; Accepted: 28 October 2019;

Published online: 03 December 2019

\section{Notes}

1 IN3 strategic plan: https://www.uoc.edu/portal/en/in3/coneix/pla-estrategic/index. html

2 UOC strategic plan: https://www.uoc.edu/portal/en/universitat/pla-estrategic/index html

3 Dimmons strategic plan: http://dimmons.net/strategic-plan-2018-2023/

$4 \mathrm{Via}$ https://voyant-tools.org/ (web-based text reading and analysis open source environment) and https://rawgraphs.io/ (open source data visualization framework).

5 SWOT analysis is a strategic planning technique used to help an organisation identify strengths, weaknesses, opportunities and threats related to project development (Osita et al., 2014).

\section{References}

Amrollahi A, Rowlands B (2017) Collaborative open strategic planning: a method and case study. Inform Technol People 30(4):832-852. https://doi.org/ 10.1108/ITP-12-2015-0310

Andersen TJ (2004) Integrating decentralized strategy making and strategic planning processes in dynamic environments. J Manag Stud 41(8):1271-1299. https://doi.org/10.1111/j.1467-6486.2004.00475.x

Argyris C, Schön DA (1989) Participatory action research and action science compared: “A commentary". Am Behav Scientist 32(5):612. https://doi.org/ 10.1177/0002764289032005008

Argyris C, Schön DA (1997) Organizational learning: a theory of action perspective. Reis 77/78:345-348. https://doi.org/10.2307/40183951

Barzelay M, Jacobsen AS (2009) Theorizing implementation of public management policy reforms: A case study of strategic planning and programming in the European Commission. Governance 22(2):319-334. https://doi.org/10.1111/ j.1468-0491.2009.01437.x

Bemelmans T (1979) Strategic planning for research and development. Long Range Planning 12(2):33-44. https://doi.org/10.1016/0024-6301(79)90071-2

Berkley S, Bertram K, Delfraissy JF, Draghia-Akli R, Fauci A, Hallenbeck C, Piot P (2010) The 2010 scientific strategic plan of the Global HIV Vaccine Enterprise. Nat Med 16(9):981. https://doi.org/10.1038/nm0910-981

Best KM, Jarrín O, Buttenheim AM, Bowles KH, Curley MA (2015) Innovation in creating a strategic plan for research within an academic community. Nurs Outlook 63(4):456-461. https://doi.org/10.1016/j.outlook.2015.01.005

Blomquist T, Hällgren M, Nilsson A, Söderholm A (2010) Project-as-practice: In search of project management research that matters. Project Manag J 41 (1):5-16. https://doi.org/10.1002/pmj.20141

Boardman C, Gray D (2010) The new science and engineering management: cooperative research centers as government policies, industry strategies, and organizations. J Technol Transfer 35(5):445-459. https://doi.org/10.1007/ s10961-010-9162-y

Bozeman B, Boardman C (2014) Assessing research collaboration studies: a framework for analysis. In: Bozeman B, Boardman C (eds) Research collaboration and team science. Springer, Cham, pp 1-11

Bryson JM (2011) Strategic planning for public and nonprofit organizations: a guide to strengthening and sustaining organizational achievement. John Wiley and Sons, San Francisco

Burke WW, Richley EA, DeAngelis L (1985) Changing leadership and planning processes at the lewis research center, national aeronautics and space administration. Human Res Manag 24(1):81-90. https://doi.org/10.1002/ hrm.3930240107

Cao L, Mohan K, Xu P, Ramesh B (2009) A framework for adapting agile development methodologies. Eur J Inform Syst 18(4):332-343. https://doi.org/ $10.1057 /$ ejis. 2009.26 
Carayannis EG, Campbell DF (2012) Mode 3 knowledge production in quadruple helix innovation systems. In Mode 3 knowledge production in quadruple helix innovation systems. Springer, New York, pp 1-63

Cervone HF (2011) Understanding agile project management methods using scrum. OCLC Syst Services 27(1):18-22. https://doi.org/10.1108/ 10650751111106528

Cervone HF (2014) Improving strategic planning by adapting agile methods to the planning process. J Library Admin 54(2):155-168. https://doi.org/10.1080/ 01930826.2014 .903371

Ciric D, Lalic B, Gracanin D, Palcic I, Zivlak N (2018) Agile project management in new product development and innovation processes: Challenges and benefits beyond software domain. In 2018 IEEE International Symposium on Innovation and Entrepreneurship (TEMS-ISIE). IEEE, pp 1-9

Derrick G, Nickson A (2014) Invisible intermediaries: a systematic review into the role of research management in university and institutional research processes. J Res Admin 45(2):11

Dooris MJ, Kelley JM, Trainer JF (2004) Strategic planning in higher education. New Direct Institut Res (123):5-11. https://doi.org/10.1002/ir.115

Drummond CN (2003) Strategic planning for research administration. J Res Admin 34(2):4

Eccles K, Schroeder R, Meyer ET, Kertcher Z, Barjak F, Huesing T, Robinson S (2009) The future of e-research infrastructures. In Proceedings of NCeSS International Conference on e-Social Science, Cologne, pp 24-26

Eppler MJ, Platts K, Kazancioglu E (2006) Visual strategizing. Università della Svizzera italiana

Eppler MJ, Platts KW (2009) Visual strategizing: the systematic use of visualization in the strategic-planning process. Long Range Planning 42(1):42-74. https:// doi.org/10.1016/j.lrp.2008.11.005

Ferlie E, Ongaro E (2015) Strategic management in public services organizations: concepts, schools and contemporary issues. Routledge

Flood RL, Jackson MC (1991) Iterative planning. In:Flood RL, Jackson MC (eds) Creative problem solving: total systems intervention. Wiley, New York, pp $143-65$

Fowler N, Lindahl M, Sköld D (2015) The projectification of university research: a study of resistance and accommodation of project management tools and techniques. Int J Manag Projects Business 8(1):9-32. https://doi.org/10.1108/ IJMPB-10-2013-0059

Fuster Morell M (2009) Action research: mapping the nexus of research and political action. Interface 1(1):21-45

Fuster Morell M (2010a) Participation in online creation communities: ecosystemic participation. Vol. 1. In Conference Proceedings of JITP 2010: The Politics of Open Source, pp 270-295

Fuster Morell M (2010b) Governance of online creation communities: provision of infrastructure for the building of digital commons. European University Institute

Fuster Morell M (2012) E-Research collaboration of international scope in social and political sciences: scale and complexity linkage with the requirement of physical encounters. In Collaborative and distributed e-research: Innovations in technologies, strategies and applications. IGI Global, pp 330-346

Giraudeau M (2008) The drafts of strategy: opening up plans and their uses. Long Range Plan 41(3):291-308. https://doi.org/10.1016/j.lrp.2008.03.001

Griggs D, Stafford-Smith M, Gaffney O, Rockström J, Öhman MC, Shyamsundar P, Noble I (2013) Policy: sustainable development goals for people and planet. Nature 495(7441):305. https://doi.org/10.1038/495305a

Hoda R, Noble J, Marshall S (2013) Self-organizing roles on agile software development teams. IEEE Transactions on Software Engineering 39(3):422-444. https://doi.org/10.1109/TSE.2012.30

Holm P, Goodsite ME, Cloetingh S, Agnoletti M, Moldan B, Lang DJ, Scholz RW (2013) Collaboration between the natural, social and human sciences in global change research. Environm Sci Policy 28:25-35. https://doi.org/ 10.1016/j.envsci.2012.11.010

Ioannidis JP, Fanelli D, Dunne DD, Goodman SN (2015) Meta-research: evaluation and improvement of research methods and practices. PLoS Biol 13(10): e1002264. https://doi.org/10.1371/journal.pbio.1002264

Jasanoff S (2003) Technologies of humility: citizen participation in governing science. Minerva 41(3):223-244. https://doi.org/10.1023/A:1025557512320

Jarzabkowski P, Spee AP (2009) Strategy-as-practice: a review and future directions for the field. Int J Manag Rev 11(1):69-95. https://doi.org/10.1111/j.1468$2370.2008 .00250 . x$

Jeffrey P (2003) Smoothing the waters: Observations on the process of crossdisciplinary research collaboration. Soc Stud Sci 33(4):539-562. https://doi. org/10.1177/0306312703334003

Kerzner H, Kerzner HR (2017) Project management: a systems approach to planning, scheduling, and controlling. John Wiley \& Sons, Hoboken

Kimbell L (2012) Rethinking design thinking: Part II. Design Cult 4(2):129-148. https://doi.org/10.2752/175470812X13281948975413

Leischow SJ, Best A, Trochim WM, Clark PI, Gallagher RS, Marcus SE, Matthews E (2008) Systems thinking to improve the public's health. Am J Prev Med 35(2): S196-S203
Lindberg T, Noweski C, Meinel C (2010) Evolving discourses on design thinking: how design cognition inspires meta-disciplinary creative collaboration. Technoetic Arts 8(1):31-37. https://doi.org/10.1386/tear.8.1.31/1

Mintzberg H (1994) The fall and rise of strategic planning. Harvard Business Rev 72(1):107-114

Naranjo-Bock C (2012) Creativity-based research: The process of co-designing with users. UX Magazine 4

Ordorika I, Lloyd M (2015) International rankings and the contest for university hegemony. J Educ Policy 30(3):385-405. https://doi.org/10.1080/ 02680939.2014 .979247

Osita C, Idoko O, Justina N (2014) Organization's stability and productivity: the role of SWOT analysis. Int J Innovat Appl Res 2(9):23-32

Owen R, Macnaghten P, Stilgoe J (2012) Responsible research and innovation: from science in society to science for society, with society. Science Public Policy 39(6):751-760. https://doi.org/10.1093/scipol/scs093

Poister TH (2010) The future of strategic planning in the public sector: linking strategic management and performance. Public Admin Rev 70(s1). https:// doi.org/10.1111/j.1540-6210.2010.02284.x

Polk R (2011) Agile and kanban in coordination. In Agile Conference (AGILE). IEEE, pp 263-268

Rand C, Eckfeldt B (2004) Aligning strategic planning with agile development: extending agile thinking to business improvement. In Agile Development Conference. IEEE, pp 78-82

Ranjan KR, Read S (2016) Value co-creation: concept and measurement. J Acad Market Sci 44(3):290-315. https://doi.org/10.1007/s11747-014-0397-2

Robinson H, Sharp H (2003) XP Culture: Why the twelve practices both are and are not the most significant thing. In Proceedings of the Agile Development Conference, 2003 ADC 2003 (12-21) IEEE. https://doi.org/10.1109/ ADC.2003.1231448

Sá CM, Tamtik M (2012) Strategic planning for academic research. Higher Education Management and Policy 24(1):1-20. https://doi.org/10.1787/hemp-24$5 \mathrm{k} 9 \mathrm{bdtj6b0r6}$

Sanders E, Brandt E, Binder T (2010) A framework for organizing the tools and techniques of participatory design. In Proceedings of the 11th Biennial Participatory Design Conference. ACM, pp 195-198

Sanders E, Stappers PJ (2008) Co-creation and the new landscapes of design. CoDesign 4(1):5-18. https://doi.org/10.1080/15710880701875068

Santos BDS (2012) The university at a crossroads. Hum Archit 10(1):3

Senabre Hidalgo E (2018a) Management of a multidisciplinary research project: a case study on adopting agile Methods. J Res Practice 14(1):2

Senabre Hidalgo E, Ferran-Ferrer N, Perelló J (2018) Participatory design of citizen science experiments. Comunicar 26(54):29-38. https://doi.org/10.3916/C542018-03

Senabre Hidalgo E (2019) Adapting the scrum framework for agile project management in science: case study of a distributed research initiative. Heliyon 5 (3): $\mathrm{e} 01447$

Sørensen MP, Bloch C, Young M (2016) Excellence in the knowledge-based economy: from scientific to research excellence. Eur J Higher Educ 6 (3):217-236. https://doi.org/10.1080/21568235.2015.1015106

Spee AP, Jarzabkowski P (2011) Strategic planning as communicative process. Organization Stud 32(9):1217-1245. https://doi.org/10.1177/0170840611411387

Spinuzzi C (2005) The methodology of participatory design. Technical Commun 52(2):163-174

Spinuzzi C (2015) All edge: Inside the new workplace networks. University of Chicago Press, Chicago, https://doi.org/10.7208/chicago/9780226237015.001.0001

Srinivasa Rao AB, Kumar PM, Aithal PS (2015) Strategic planning in higher education institutions: A case study of SIMS-VISION 2025. International Journal of Educational Science and Research (IJESR), pp 2249-6947

Visser FS, Stappers PJ, Van der Lugt R, Sanders EB (2005) Contextmapping: experiences from practice. CoDesign 1(2):119-149. https://doi.org/10.1080/ 15710880500135987

Voorberg WH, Bekkers VJ, Tummers LG (2015) A systematic review of cocreation and co-production: embarking on the social innovation journey. Public Manag Rev 17(9):1333-1357. https://doi.org/10.1080/14719037. 2014.930505

Vostal F (2016) Accelerating academia: the changing structure of academic time. Palgrave Macmillan, UK. https://doi.org/10.1057/9781137473608

Wang J, Hicks D (2015) Scientific teams: self-assembly, fluidness, and interdependence. J Informat 9(1):197-207. https://doi.org/10.1016/j.joi.2014.12.006

Whittington R (1996) Strategy as practice. Long Range Plan 29(5):731-735. https:// doi.org/10.1016/0024-6301(96)00068-4

Wilbon AD (2012) Interactive planning for strategy development in academicbased cooperative research enterprises. Technol Analysis Strat Manag 24 (1):89-105. https://doi.org/10.1080/09537325.2012.643564

Wilson I (1994) Strategic planning isn't dead-it changed. Long Range Plan 27 (4):12-24. https://doi.org/10.1016/0024-6301(94)90052-3

Wolf C, Floyd SW (2017) Strategic planning research: toward a theory-driven agenda. J Manag 43(6):1754-1788. https://doi.org/10.1177/0149206313478185 
Wuchty S, Jones BF, Uzzi B (2007) The increasing dominance of teams in production of knowledge. Science 316(5827):1036-1039. https://doi.org/10.1126/ science.1136099

\section{Competing interests}

The authors declare no competing interests.

\section{Additional information}

Correspondence and requests for materials should be addressed to E.S.H. or M.F.M.

Reprints and permission information is available at http://www.nature.com/reprints

Publisher's note Springer Nature remains neutral with regard to jurisdictional claims in published maps and institutional affiliations. (c) (i) Open Access This article is licensed under a Creative Commons Attribution 4.0 International License, which permits use, sharing, adaptation, distribution and reproduction in any medium or format, as long as you give appropriate credit to the original author(s) and the source, provide a link to the Creative Commons license, and indicate if changes were made. The images or other third party material in this article are included in the article's Creative Commons license, unless indicated otherwise in a credit line to the material. If material is not included in the article's Creative Commons license and your intended use is not permitted by statutory regulation or exceeds the permitted use, you will need to obtain permission directly from the copyright holder. To view a copy of this license, visit http://creativecommons.org/ licenses/by/4.0/.

(C) The Author(s) 2019 